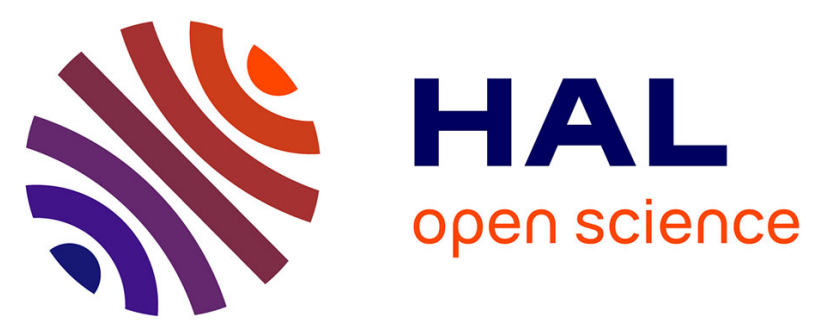

\title{
Correlation between the retroversion of the humeral head and the orientation of the intertubercular sulcus: a CT scan anatomical study
}

Daphne Guenoun, Thomas Le Corroller, Aude Lagier, Vanessa Pauly, Pierre Champsaur

\section{To cite this version:}

Daphne Guenoun, Thomas Le Corroller, Aude Lagier, Vanessa Pauly, Pierre Champsaur. Correlation between the retroversion of the humeral head and the orientation of the intertubercular sulcus: a CT scan anatomical study. Surgical and Radiologic Anatomy, 2015, 37 (4), pp.357-361. 10.1007/s00276014-1354-y . hal-01453416

\author{
HAL Id: hal-01453416 \\ https://hal.science/hal-01453416
}

Submitted on 21 Mar 2017

HAL is a multi-disciplinary open access archive for the deposit and dissemination of scientific research documents, whether they are published or not. The documents may come from teaching and research institutions in France or abroad, or from public or private research centers.
L'archive ouverte pluridisciplinaire HAL, est destinée au dépôt et à la diffusion de documents scientifiques de niveau recherche, publiés ou non, émanant des établissements d'enseignement et de recherche français ou étrangers, des laboratoires publics ou privés. 


\title{
Correlation between the retroversion of the humeral head and the orientation of the intertubercular sulcus: a CT scan anatomical study
}

\author{
Daphne Guenoun - Thomas Le Corroller • \\ Aude Lagier • Vanessa Pauly • Pierre Champsaur
}

Received: 11 April 2014/Accepted: 21 July 2014/Published online: 13 August 2014

(C) Springer-Verlag France 2014

\begin{abstract}
Purpose The purpose was to study the anatomy of the humeral head, more specifically the retroversion of the humeral head and the orientation of the intertubercular sulcus, using CT scan, and to make correlations between those two entities of the proximal humerus.

Methods Sixty dry adult humeri from an osteological collection underwent $\mathrm{CT}$ scan from the proximal to the distal extremity. The measurements obtained by CT-reformation were recorded by two independent radiologists. We determined the humeral head axis, the transepicondylar axis, the retroversion of the humeral head, and the orientation of the intertubercular sulcus (ITS). Statistical analysis using SPSS determined the Pearson correlation coefficient.
\end{abstract}

D. Guenoun $(\varangle) \cdot$ T. Le Corroller · P. Champsaur Radiology Department, APHM, Hôpital Sainte Marguerite, 13009 Marseille, France

e-mail: daph.guenoun@gmail.com

T. Le Corroller

e-mail: Thomas.LeCorroller@ap-hm.fr

P. Champsaur

e-mail: Pierre.champsaur@ap-hm.fr

A. Lagier

Department of Otorhinolaryngology, APHM,

Hôpital de La Timone, Marseille, France

e-mail: Aude.lagier@ap-hm.fr

V. Pauly

Department of Public Health, EA3279 Self-perceived Health

Assessment Research Unit, APHM, Marseille, France

e-mail: Vanessa.pauly@ap-hm.fr
Results The CT scan measurements were similar to those in the literature, and thus allowed us to validate CT scan assessment. Statistical analysis showed a significant reverse correlation [the coefficient of correlation was $-0.37(p=0.004)]$ between the retroversion of the humeral head and the orientation of the intertubercular sulcus: the more the retroversion of the humeral head increases, the more the angle of the orientation of the ITS decreases. Conclusions To the best of our knowledge, this reverse correlation between the retroversion of the humeral head and the orientation of the intertubercular sulcus has never been described. This new anatomical data might be helpful for orthopedic surgery.

Keywords Humeral head · Anatomy · Intertubercular sulcus - CT scan

\section{Introduction}

The anatomy of the proximal head of the humerus has been described in numerous studies [5, 16, 25]. The retroversion of the humeral head and the orientation of the intertubercular sulcus are two bony features of the proximal humerus that may be considered in the pathogenesis of chronic anterior shoulder instability [4, 6-8].

The aim of our work was to add possibly critical information to the knowledge on humeral head anatomy, which might help in orthopedic surgery. In addition to addressing methodological issues such as how to determine the retroversion of the humeral head by CT scan, we propose new, practically relevant measures such as the orientation of the intertubercular sulcus, using an easy method. Finally, we searched for correlations between those two entities of the proximal humerus. 


\section{Materials and methods}

We collected 60 dry adult humeri. This series was constituted by skeletons preserved in the department of biological Anthropology at our institution. The 60 dry adult humeri were analyzed by multiplanar computed tomography (CT) (Elscint CT Twin; Marconi, Haifa, Israël). CT data were transferred to a workstation (Silicon Grafics; Sunnyvale, CA) for multiplanar CT-reformation. The measurements obtained by CT-reformation were recorded by two independent radiologists in the following way. The humeral head axis was defined as that perpendicular to the anatomical neck taken to the periphery of the articular cartilage. However, this study was performed on dry bones so we used the subchondral plate instead of the articular cartilage as the landmark. The subchondral bone plate consists of two mineralized layers, which together form a single unit separating the articular cartilage from the bone marrow [17]. There is a discrete band of mineralized cartilage on the articular side of the plate of the line of contact between plate and cartilage, which is well visualized on CT scan.

The transepicondylar axis was defined by a line joining the most medial and the most lateral extremities of the distal humerus. The angle of humeral retroversion is the angle between the humeral head axis and the transepicondylar axis (Fig. 1).

We measured the ITS width on a horizontal CT-reformation in a plane passing by the greater and lesser tubercles and the intertubercular sulcus. The line perpendicular at the intertubercular line is the ITS axis. Intertubercular sulcus orientation was defined by the angle between the intertubercular sulcus axis and the humeral head axis (Fig. 2).

The correlation between humeral head retroversion and the intertubercular sulcus orientation was analyzed using Pearson correlation coefficient. Statistical analysis was conducted using SPSS for Windows. The correlation was considered significant if the $p$ value was lower than or equal to $5 \%$.

\section{Results}

The results (mean values) are from 60 dry adult humeri. The mean retroversion angle of the humeral head in relation of the transepicondylar axis was $12.3^{\circ}$. The mean ITS orientation was $40.7^{\circ}$. The Pearson correlation coefficient between the retroversion of the humeral head and the ITS orientation was -0.37 (95\% confidence interval $=[-0.974 ;-0.11]$ and $p=0.004)$. There was an inverse correlation between the retroversion of the humeral head and the ITS orientation (Table 1 and Fig. 3).
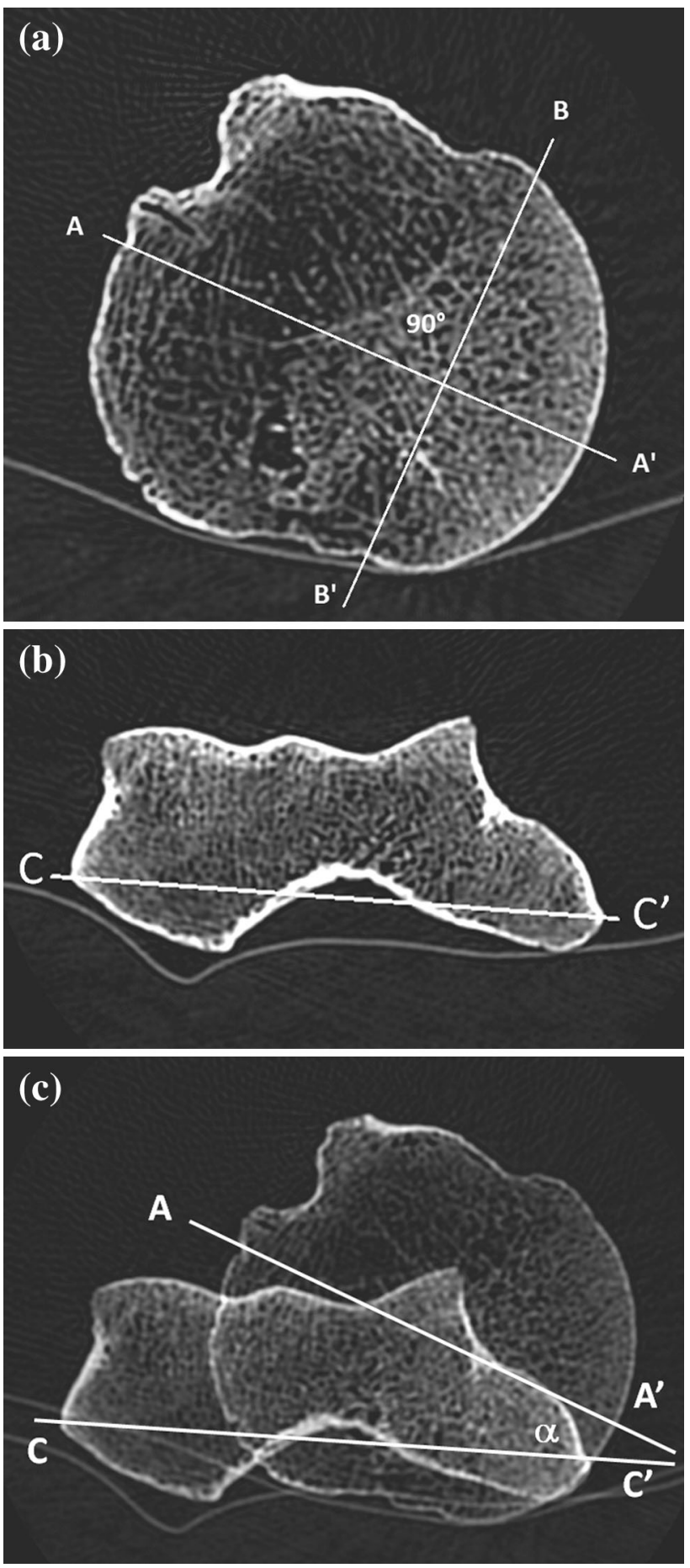

Fig. 1 Humeral retroversion on CT scan reformation. a humeral head axis $\left(\mathrm{AA}^{\prime}\right)$ is the line perpendicular to the anatomical neck taken to the periphery of the subchondral plate. $\mathbf{b}$ the transepicondylar axis $\left(\mathrm{CC}^{\prime}\right)$ is the line joining the most medial and the most lateral extremities of the distal humerus. $\mathbf{c}$ The angle of humeral retroversion $(\alpha)$ is the angle between the humeral head axis $\left(\mathrm{AA}^{\prime}\right)$ and the transepicondylar axis $\left(\mathrm{CC}^{\prime}\right)$

Measurements by two independent musculoskeletal radiologists, with 6 and 20 years of experience, were recorded for each humerus. No significant intraobserver 


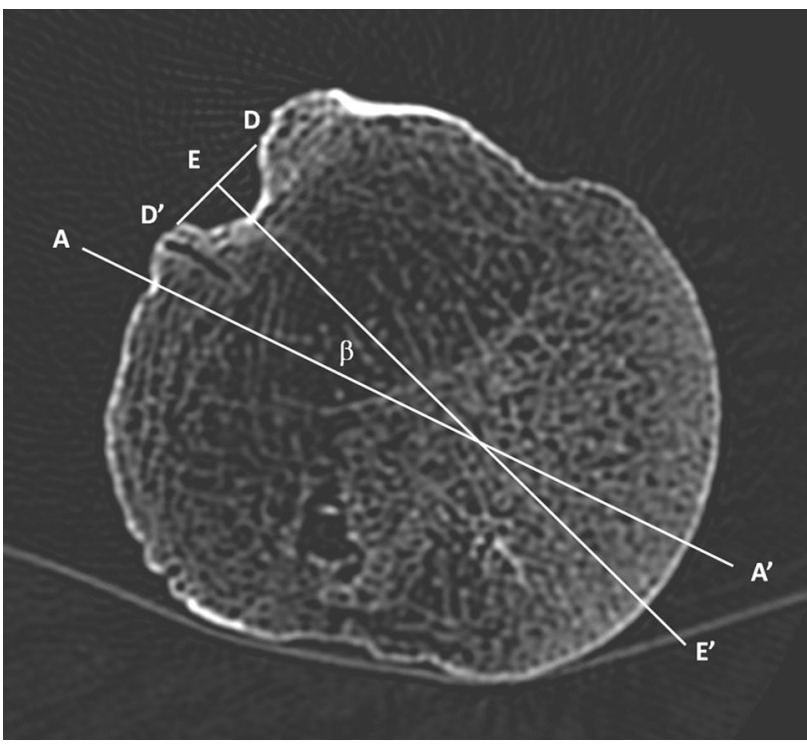

Fig. 2 Intertubercular sulcus orientation. The ITS axis $\left(\mathrm{EE}^{\prime}\right)$ is the line perpendicular at the intertubercular line $\left(\mathrm{DD}^{\prime}\right)$. ITS orientation $(\beta)$ was defined by the angle between the intertubercular sulcus axis $\left(\mathrm{EE}^{\prime}\right)$ and the humeral head axis $\left(\mathrm{AA}^{\prime}\right)$

Table 1 Pearson correlation coefficient between the retroversion of the humeral head and the ITS orientation

\begin{tabular}{lcclcc}
\hline In degree & $N$ & Mean \pm SD & $\begin{array}{l}\text { Median } \\
{[\mathrm{IQR}]}\end{array}$ & Min & Max \\
\hline $\begin{array}{l}\text { Retroversion humeral } \\
\text { head }\end{array}$ & 60 & $12.3 \pm 7.9$ & $10[7 ; 17.5]$ & 2 & 45 \\
\begin{tabular}{l} 
ITS orientation \\
\hline
\end{tabular} & 60 & $40.7 \pm 13$ & $40[30 ; 50]$ & 14 & 70 \\
\hline
\end{tabular}

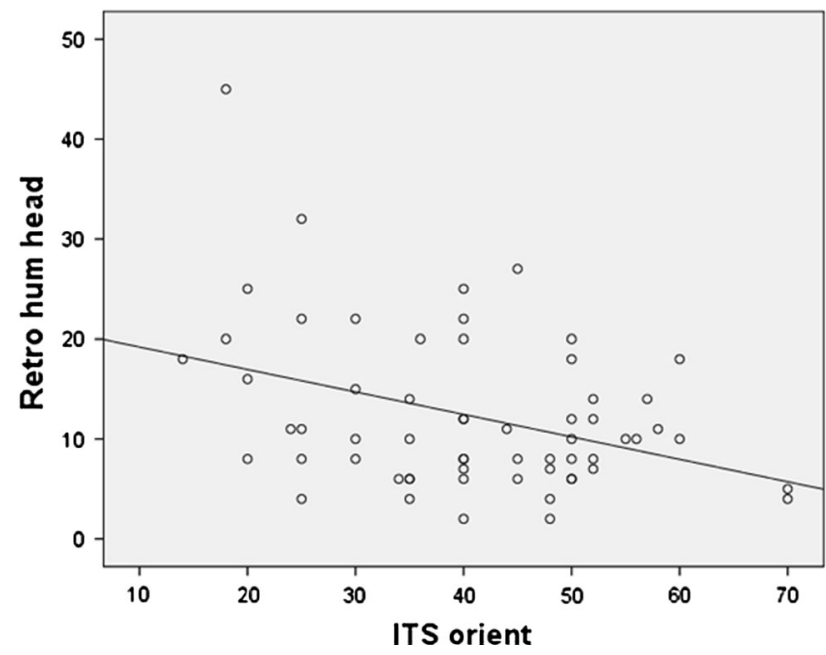

Fig. 3 Reverse correlation between the retroversion of the humeral head and the ITS orientation variability or interobserver variability was found using ANOVA test with a significance level at 0.05 .

\section{Discussion}

In our study, the mean humeral retroversion angle of $12.31^{\circ}$ confirms other anatomical studies, which found mean normal values that were quite variable, from $9^{\circ}$ to $40^{\circ}[3,6]$. This variation is due to several factors, including the definition of humeral head retroversion, different methods of measurement, ranges of normal values, and accuracy of anatomic landmarks to guide determination of anatomic retroversion. Humeral head retroversion is generally defined with respect to the plane of the humeral head articular surface proximally; distally, however, the reference axis has been debated, including the transepicondylar axis [3, 4, 8], trochlear tangent axis [7, 9, 14, 19] and forearm axis [8, 18]. Methods of measurement have included direct anatomic [13, 15], radiographic [4, 14], ultrasound [10], computed tomography scan [3, 8], MRI [6], and computer-assisted methods [5, 19, 21, 22]. Boileau et al. [2] showed that the radiographic method overestimated the humeral head retroversion relative to the computer-assisted method. However, there was no difference between humeral head retroversion obtained by the CT scan method, the direct method, and the computer-assisted method.

In our study, the mean ITS orientation was $40.7^{\circ}$. We defined ITS orientation as the angle between the intertubercular sulcus axis and the humeral head axis. Rockwood et al. [23] found a mean ITS orientation of $45^{\circ}$. Many authors studied the anatomy of the intertubercular sulcus $[19,21,24]$, and some tried to define the relation with the humeral head retroversion [3, 6, 12]. Doyle and Burks [6] measured the distance from the biceps groove to a line perpendicular to the midpoint of the humeral articular surface. Then they studied the relation between the biceps distance and the retroversion angle of the humeral head. They found that the biceps distance average was $11.8 \mathrm{~mm}$, whereas retroversion average was $26.8^{\circ}$. They concluded that placing the fin of a humeral head implant $12 \mathrm{~mm}$ posterior to the biceps groove reproduces normal anatomy better than the use of an arbitrary standard of $30^{\circ}-40^{\circ}$ retroversion.

Cassagnaud et al. [3] measured the intertubercular sulcus and transepicondylar axis creating the angle of lateralization of the intertubercular sulcus. This method requires choosing four CT sections and superimposing them on a single plane. The average values of lateralization of the intertubercular sulcus were between $115^{\circ}$ and $122^{\circ}$.

Our method of measurement seems easier, logical and reproducible. Furthermore, we found an inverse correlation 
between the retroversion of the humeral head and the ITS orientation. The more the retroversion of the humeral head increases, the more the ITS orientation angle decreases. This inverse correlation highlights the intervention of the tendon of the long head of the biceps in the mechanism of the retroversion of the humeral head. The biceps brachii muscle is generally considered to be a supinator of the forearm and a flexor of the elbow. However, the biceps crosses the glenohumeral joint and the elbow. As it passes to its insertion in the supraglenoid region, the tendon of the long head of the biceps occupies an intra-articular position in the shoulder. Some authors demonstrated that the long head of the biceps may function to stabilize the glenohumeral joint $[11,18,20]$. It has been suggested that using the bicipital groove as a landmark for placing the prosthesis might reproduce normal anatomy [1]. Indeed, the anatomy of the proximal humerus was highly variable for medial offset, tuberosity offset, and retrotorsion [9]. Yet, the practically relevant variance was minimal for the inclination of the humeral head, the head radius-height ratio, and the distance between the bicipital groove to the equator [9]. These findings have pertinent implications for prosthetic design and implantation. Our study is the first that shows an inverse correlation between the humeral head retroversion and the intertubercular sulcus orientation. This anatomical datum could help in the design of humeral head prostheses.

However, several limitations may be considered inherent to the materials and methods. The anthropometric angle measurements were made using CT scan imaging. Thus, our data were not directly obtained from cadaver dissection, but from multiplanar CT-reformation. However, CT scan imaging facilitated precise and reproducible drawing of the axis and angles.

Another limitation is the low number of humeri: another study including a higher number of humeri could confirm this reverse correlation and find a better coefficient of correlation, closer to -1 . Finally, this is an anthropometric study but such measurements could be easily realized for patients who undergo shoulder CT scan before prosthesis, by making an additional low-dose section on the epicondyle, after the authorization of patients and ethics committees.

\section{Conclusion}

The measurements of humeral retroversion and the intertubercular sulcus orientation by the CT method are easy to realize and in agreement with the data of the literature. There is a reverse correlation between the retroversion of the humeral head and the orientation of the intertubercular sulcus. To the best of our knowledge, this is the first study to describe this correlation. These additional anatomical data might improve knowledge of the humeral head anatomy and be helpful for orthopedic surgery.

Conflict of interest There was no conflict of interest.

\section{References}

1. Ballmer FT, Sidles JA, Lippitt SB, Matsen FA 3rd (1993) Humeral head prosthetic arthroplasty: surgically relevant geometric considerations. J Shoulder Elb Surg Am Shoulder Elb Surg Al 2(6):296-304. doi:10.1016/1058-2746(93)90075

2. Boileau P, Bicknell RT, Mazzoleni N, Walch G, Urien JP (2008) CT Scan method accurately assesses humeral head retroversion. Clin Orthop 466(3):661-669. doi:10.1007/s11999-007-0089

3. Cassagnaud X, Maynou C, Petroff E, Dujardin C, Mestdagh H (2003) A study of reproducibility of an original method of CT measurement of the lateralization of the intertubercular groove and humeral retroversion. Surg Radiol Anat SRA 25(2):145-151. doi:10.1007/s00276-003-0101-6

4. Cyprien JM, Vasey HM, Burdet A, Bonvin JC, Kritsikis N, Vuagnat $\mathrm{P}$ (1983) Humeral retrotorsion and glenohumeral relationship in the normal shoulder and in recurrent anterior dislocation (scapulometry). Clin Orthop 175:8-17

5. DeLude JA, Bicknell RT, MacKenzie GA, Ferreira LM, Dunning CE, King GJW et al (2007) An anthropometric study of the bilateral anatomy of the humerus. J Shoulder Elb Surg Am Shoulder Elb Surg Al 16(4):477-483. doi:10.1016/j.jse.2006.09.016

6. Doyle AJ, Burks RT (1998) Comparison of humeral head retroversion with the humeral axis/biceps groove relationship: a study in live subjects and cadavers. J Shoulder Elb Surg Am Shoulder Elb Surg Al 7(5):453-457. doi:10.1016/S10582746(98)90193-8

7. Edelson G (1999) Variations in the retroversion of the humeral head. J Shoulder Elb Surg Am Shoulder Elb Surg Al 8(2):142-145. doi:10.1016/S1058-2746(99)90007-1

8. Hernigou P, Duparc F, Hernigou A (2002) Determining humeral retroversion with computed tomography. J Bone Joint Surg Am 84-A(10): 1753-1762

9. Hertel R, Knothe U, Ballmer FT (2002) Geometry of the proximal humerus and implications for prosthetic design. J Shoulder Elb Surg Am Shoulder Elb Surg Al 11(4):331-338. doi:10.1067/ mse.2002.124429

10. Ito N, Eto M, Maeda K, Rabbi ME, Iwasaki K (1995) Ultrasonographic measurement of humeral torsion. J Shoulder Elb Surg Am Shoulder Elb Surg Al 4(3):157-161

11. Itoi E, Kuechle DK, Newman SR, Morrey BF, An KN (1993) Stabilising function of the biceps in stable and unstable shoulders. J Bone Joint Surg Br 75(4):546-550

12. Jonhson JW, Thostenson JD, Suva LJ, Hasan SA (2013) Relationship of bicipital groove rotation with humeral head retroversion: a three-dimensional computed tomographic analysis. J Bone Joint Surg Am 95(8):719-724. doi:10.2106/JBJS.J.00085

13. Krahl VE (1944) An apparatus for measuring the torsion angle in long bones. Science 99(2581):498. doi:10.1126/science.99.2581.498

14. Kronberg M, Broström LA (1990) Humeral head retroversion in patients with unstable humeroscapular joints. Clin Orthop 260:207-211

15. Kummer FJ, Perkins R, Zuckerman JD (1998) The use of the bicipital groove for alignment of the humeral stem in shoulder arthroplasty. J Shoulder Elb Surg Am Shoulder Elb Surg Al. 7(2):144-146

16. Le Corroller T, Aswad R, Pauly V, Champsaur P (2009) Orientation of the rotator cuff insertion facets on the humerus: comparison between individuals with intact and torn rotator cuffs. 
Ann Anat Anat Anz Off Organ Anat Ges 191(2):218-224. doi:10. 1016/j.aanat.2008.10.003

17. Madry H, Van Dijk C, Mueller-Gerbl M (2010) The basic science of the subchondral bone 18:419-433. doi:10.1007/s00167-0101054-Z

18. Ovesen J, Nielsen S (1985) Prosthesis position in shoulder arthroplasty. A cadaver study of the humeral component. Acta Orthop Scand 56(4):330-331

19. Oztuna V, Oztürk H, Eskandari MM, Kuyurtar F (2002) Measurement of the humeral head retroversion angle. A new radiographic method. Arch Orthop Trauma Surg 122(7):406-409. doi:10.1007/s00402-002-0398-3

20. Pagnani MJ, Deng XH, Warren RF, Torzilli PA, O'Brien SJ (1996) Role of the long head of the biceps brachii in glenohumeral stability: a biomechanical study in cadavera. J Shoulder Elb Surg Am Shoulder Elb Surg Al. 5(4):255-262. doi:10.1016/ S1058-2746(96)80051-6
21. Roberts SN, Foley AP, Swallow HM, Wallace WA, Coughlan DP (1991) The geometry of the humeral head and the design of prostheses. J Bone Joint Surg Br 73(4):647-650

22. Robertson DD, Yuan J, Bigliani LU, Flatow EL, Yamaguchi K (2000) Three-dimensional analysis of the proximal part of the humerus: relevance to arthroplasty. J Bone Joint Surg Am 82-A(11):1594-1602

23. Rockwood CA (1998) The Shoulder. Saunders, Elsevier

24. Selvaraj KG, Selvakuhmar V, Indrasingh I, Chandi G (1998) Handedness identification from intertubercular sulcus of the humerus by discriminant function analysis. Forensic Sci Int 98(1-2):101-108

25. Ueberham K, Le Floch-Prigent $P$ (1998) Intertubercular sulcus of the humerus: biometry and morphology of 100 dry bones. Surg Radiol Anat SRA. 20(5):351-354 